\title{
Biotech giant helps itself without swallowing Galapagos whole
}

\author{
A ten-year collaboration gives biotech giant Gilead first rights to all of Galapagos's pipeline.
}

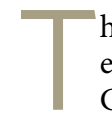
he interesting part of Gilead's expansive R\&D collaboration with Galapagos is what it claims it is not: an acquisition. Instead, Gilead-helmed by Roche veteran Daniel O’Day—not only has paid Galapagos \$3.95 billion up front, but also has bought $\$ 1.1$ billion of company equity to both ensure access to its drug pipeline for the next ten years and prevent competitors from buying the group. The partners' fortunes are tied, but they remain separate entities-for now. Some observers are drawing parallels with Roche's former archetypal partnership with Genentech or Sanofi's 2015 partnership with Regeneron.

At the heart of the deal is Galapagos's new Janus associated kinase-1 (JAK1) selective inhibitor filgotinib. The companies began working together on the anti-inflammatory drug in 2015, after AbbVie declined an option on the compound; in March 2019, the partners released positive phase 3 results in rheumatoid arthritis. With the recent deal, Gilead and Galapagos maintain the original agreement, and in addition Gilead gains full rights to GLPG1690, a phase 3 candidate for idiopathic pulmonary fibrosis (IPF), US option rights to osteoarthritis candidate GLPG1972, in phase 2b, and option rights outside Europe on all of Galapagos's other current and future clinical programs. The equity investment increases Gilead's stake in the Mechelen, Belgium-based group from $12.3 \%$ to $22 \%$; but a stand-still agreement-a contractual measure designed to prevent a hostile takeover-prevents Gilead from increasing its stake beyond a $29.9 \%$ maximum or seeking to buy Galapagos for the ten-year duration of the deal.

Critically, Galapagos maintains its research and discovery independence. The biotech "is free to follow the science. We are not going to influence them," says O’Day, The Belgian group will fund and lead discovery and development until the end of phase 2, after which Gilead's options kick in. If an option is exercised, the partners will co-develop the compound and share costs equally. The companies have agreed on specific payment terms for the IPF and osteoarthritis candidates, and a simpler licensing deal template for all future programs.

Gilead's cash allows Galapagos to rapidly expand its discovery efforts beyond its existing focus. The biotech's R\&D

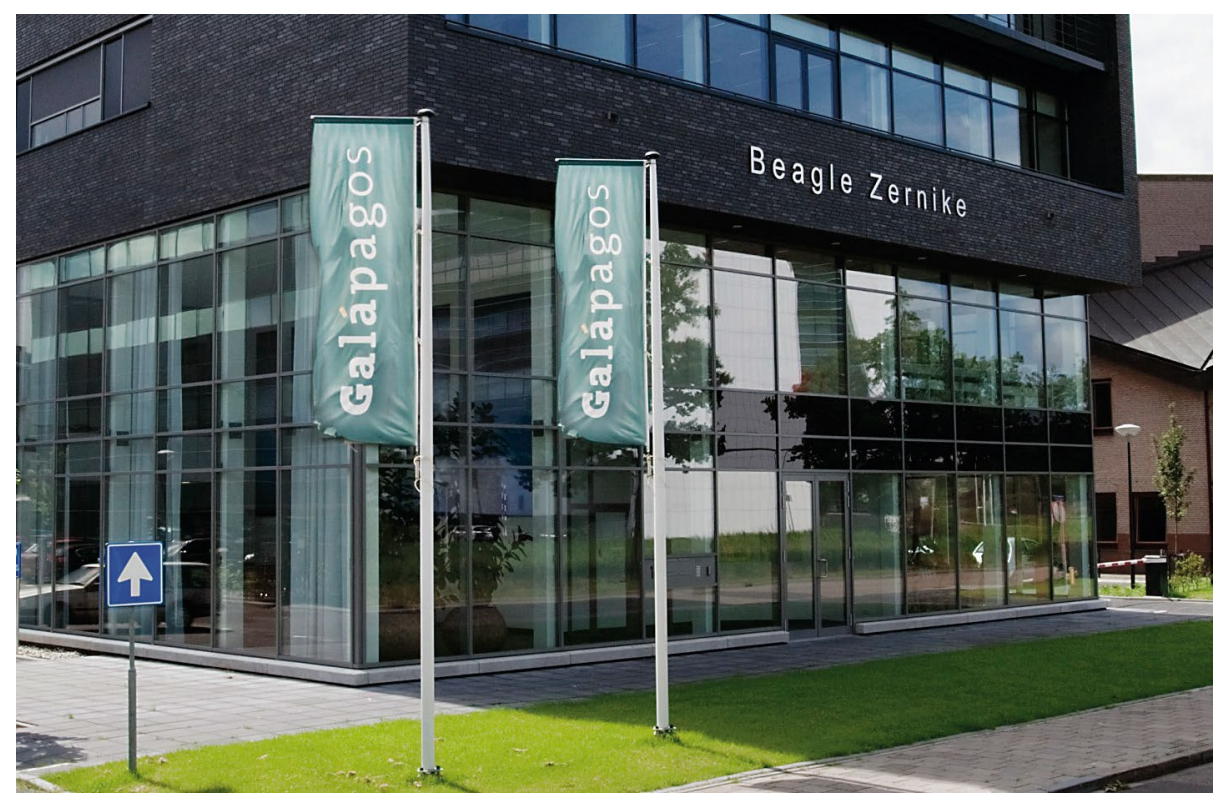

Galapagos's offices in Leiden, the Netherlands. Credit: Galapagos

platform uses a battery of human cellbased assays to identify novel drug targets. Human primary cells from an affected tissue of interest are transfected with a library of 25,000 adenoviruses encoding short interfering RNAs (siRNAs) against mRNA sequences encoded by target genes. Targets identified as pivotal in disease in the screen are then further validated and tested against collections of small molecules to identify chemical binders that mimic siRNA. Galapagos's discovery pipeline has already generated 20 pre-clinical and 7 clinical small-molecule drug candidates. The partners hope to further increase that productivity, as Galapagos plans to double its R\&D headcount to 1,000 and seek complementary technologies.

As well as turbocharging its $\mathrm{R} \& \mathrm{D}$ engine, this deal also keeps alive Galapagos's ambition to become a fully integrated, commercial-stage biotech-a vision shared by many biotechs but achieved by few. The companies have now amended their 2015 licensing agreement around filgotinib to give Galapagos expanded commercial rights in key European countries and exclusive rights in the Benelux countries. In exchange, Galapagos is on the hook for half of global development costs, rather than $20 \%$ as in the previous arrangement, but the biotech also retains generous $20-30 \%$ tiered royalties on non-European Union sales and is eligible for $\$ 1.27$ billion in potential milestones.

Industry is rife with examples of creative biotechs that are acquired by innovationhungry pharmaceutical companies, only to end up smothered and unproductive within the larger organization. Europe has fared particularly badly at retaining and growing independent biotechs. One notable exception: Allschwil, Switzerland-based Actelion, which built a multi-million-dollar commercial enterprise before selling to Johnson \& Johnson in 2017 for \$30 billion. Emerging biotech giant Ablynx, based in Ghent, Belgium, was subsumed within Paris-based Sanofi in 2018 just as its lead asset neared approval.

Galapagos CEO and founder Onno van de Stolpe has long been vocal in his desire to avoid selling out to big pharma. Before the 2015 deal, Gilead had openly sought an acquisition, but van de Stolpe claims he quickly shut down that idea. This time around, he was feeling "vulnerable" to an unsolicited takeover after filgotinib's positive phase 3 results in March 2019, and 
uncertain over what to expect from Gilead. The US biotech was undergoing a change of leadership_O'Day started on March 1 of this year-and its plans were unclear. At the time, however, "there was no concrete acquisition offer from Gilead, or from anyone else."

Gilead could have approached Galapagos's major shareholders directly with an acquisition offer, bypassing the CEO. (Those shareholders include a Rotterdam, Netherlands-based family office, Van Herk Investments, which was also one of the largest holders of Ablynx stock and, despite being a self-declared long-term investor, happily accepted the $100 \%$ premium offered by Sanofi.) But they did not. "When a company is successful, it is difficult [for the potential acquirer] to go hostile," says Geoffrey Porges, director of therapeutics research and a senior research analyst at SVBLeerink. Buying a company against management's wishes, by seeking shareholders' approval directly, spoils the creative culture that often underpins much of the deal's value, sending founders and loyal scientists fleeing. That scenario would not serve Gilead, under pressure to deploy its $\$ 30$ billion cash pile (courtesy of its legacy hepatitis $C$ virus drug franchise and an expanding HIV therapy portfolio) to enhance the pipeline. "It takes time to build a productive drug discovery platform," says O'Day, acknowledging the need for both the technology and Galapagos scientists' knowhow in applying it. "This [deal] is a major step forward for Gilead's portfolio. It doubles our research base and significantly increases our IP, expertise and capabilities in fibrosis," he said on a 14 July conference call.

This deal was designed so that Gilead could tap into its smaller partner's innovation without squashing it and shows how all pharma and biotech should work together, according to van de Stolpe. The tie-up shares some similarities with both Roche-Genentech and Sanofi's 2015 immuno-oncology partnership with Regeneron, both of which "involved cash for research, equity, board seats and defined terms for future development and commercialization," says Porges. (This year, Sanofi and Regeneron narrowed down their collaboration around two clinical-stage assets.) Whether the Gilead-Galapagos variation proves inspirational to pharma or biotech in the future will depend on how many of Galapagos's drug candidates actually succeed. If just one does, Gilead may have overpaid. If several do, the US company has gotten a great deal and Galapagos's shareholders may feel they were sold short.

Granted, the deal removes the risk of an unwanted acquisition, meets Galapagos's fundraising needs for the next ten years, and puts a floor under its share price. But it also caps that share price by snuffing out any upside from merger speculation. The European biotech has also relinquished valuable US rights to any drugs that do succeed and will bear increased development costs. Some observers also question how independent the biotech will really be because the new deal gives Gilead two members on the board who could "potentially veto anything they don't like," cautions one former biotech CEO, who suggests the deal is "an acquisition in all but name."

The deal may not be a slam dunk for Gilead, either. Galapagos's R\&D engine has been productive so far, but has yet to generate a marketed drug. Filgotinib will probably be approved, perhaps as a safer alternative to existing JAK inhibitors like Eli Lilly's Olumiant (baricitinib) and Pfizer's Xeljanz (tofacitinib), which come with serious side-effects. (The higher dose of Xeljanz received a boxed warning in ulcerative colitis in late July 2019). But following late into a very crowded, big-pharma-dominated rheumatoid arthritis market will not be easy, either in the United States or Europe, where cheaper biosimilars of AbbVie's best-selling Humira (adalimumab) are starting to push down prices. "The investment community does not share Gilead's confidence in filgotinib," says Porges. And it is unlikely that both the IPF and osteoarthritis development candidates hit the jackpot.

O'Day is looking beyond these two candidates, though. He's eyeing the almost two dozen preclinical assets, including some that appear to both stimulate anti-inflammatory cytokines and inhibit pro-inflammatory cytokines. "One or two compounds per year could come into the clinic-or more, given increased funding. I am at peace if [the] osteoarthritis and IPF [candidates] don't hit. You have to be long-term minded when approaching discovery research," says O'Day. Van de Stolpe insists that oncology remains off the table because the company's discovery platform, using primary human cells rather than cell lines, provides insufficient competitive edge in this indication.

For now, Gilead has a tight, but friendly, hold on Galapagos in a deal structure that has many positives for both sides. Yet "you never know how things go. If the market economics make sense for Gilead to buy [Galapagos], even a stand-still agreement is still negotiable," says Dharminder Chahal, investment manager at Van Herk Investments.

\section{Melanie Senior}

London, UK

Published online: 21 August 2019

https://doi.org/10.1038/d41587-019-00024-5

\section{New antibodies best ZMapp in Ebola trial}

Two antibody therapies for Ebola have performed well in a late-stage clinical trial being conducted during the Ebola outbreak in the Democratic Republic of the Congo. The study, called PALM (an abbreviation for a Swahili phrase meaning "together save lives") was testing Regeneron's REGN-EB3, a collection of three fully human monoclonal antibodies; Ridgeback Biotherapeutics single monoclonal antibody mAb114; the nucleotide-analog antiviral remdesivir, developed by Gilead Sciences; and Mapp Biopharmaceutical's ZMapp, a cocktail of monoclonal antibodies against Ebola glycoproteins. ZMapp, the only candidate drug previously studied in Ebola patients, was being used as the control arm in PALM because it showed a favorable survival trend in an earlier trial. Following an August review, an independent data and safety monitoring board (DSMB) stopped the trial of the four therapies, recommending that participants now be randomized to receive only REGN-EB3 or mAb114. The preliminary PALM data showed a $29 \%$ mortality rate for participants treated with REGN-EB3 and 34\% with mAb114, versus 53\% with remdesivir and 49\% with ZMapp.

"It was clear to the DSMB that those agents are more effective than the other two," NIAID director Anthony Fauci said in an audio briefing. "Today, we have taken new steps. From now on, we will no longer say that EBOV is not curable," added PALM principal investigator Jean-Jacques Muyembe-Tamfum.

A week before the PALM trial announcement, the Sabin Vaccine Institute licensed rights to three vaccine candidates, including a phase 2 vaccine against Ebola, from GlaxoSmithKline.

Published online: 2 October 2019 https://doi.org/10.1038/s41587-019-0284-y 